\title{
FUZZY APPLICATIONS IN A POWER STATION
}

\author{
T.K Sai ${ }^{1}$ and K.A. Reddy ${ }^{2}$ \\ ${ }^{1}$ NTPC, India \\ ${ }^{2} \mathrm{KITSW}$, India
}

\begin{abstract}
Power generation today is an increasingly demanding task, worldwide, because of emphasis on efficient ways of generation. A power station is a complicated multivariable controlled plant, which consists of boiler, turbine, generator, power network and loads. The power sector sustainability depends on innovative technology and practices in maintaining unit performance, operation, flexibility and availability. The demands being placed on Control \& Instrumentation engineers include economic optimization, practical methods for adaptive and learning control, software tools that place state-of-art methods. As a result, Fuzzy techniques are explored which aim to exploit tolerance for imprecision, uncertainty, and partial truth to achieve robustness, tractability, and low cost. This paper proposes use of fuzzy techniques in two critical areas of Soot Blowing optimization and Drum Level Control.

Presently, in most of the Power stations the soot blowing is done based on a fixed time schedule. In many instances, certain boiler stages are blown unnecessarily, resulting in efficiency loss. Therefore an fuzzy based system is proposed which shall indicate individual section cleanliness to determine correct soot blowing scheme. Practical soot blowing optimization improves boiler performance, reduces NOx emissions and minimizes disturbances caused by soot blower activation. Due to the dynamic behaviour of power plant, controlling the Drum Level is critical. If the level becomes too low, the boiler can run dry resulting in mechanical damage of the drum and boiler tubes. If the level becomes too high, water can be carried over into the Steam Turbine which shall result in catastrophic damage. Therefore an fuzzy based system is proposed to replace the existing conventional controllers
\end{abstract}

\section{KEYWORDS}

Artificial intelligence, Expert Systems, Fuzzy Logic, Power generation, Soot Blowers, Drum Level

\section{INTRODUCTION}

The Government owned Power station in India that has been considered in this paper is a Fossil fired $500 \mathrm{MW}$ Power Station. The overview of a $500 \mathrm{MW}$ unit is shown in figure 1. The Soot blowing system consists of 88 Wall Blowers in a $500 \mathrm{MW}$ Coal based power plant in India. The paper presents a Fuzzy rule-based system to estimate the cleanliness factor of the boiler. The cleanliness factor is calculated based on certain identified variables. The Drum level control strategies are reviewed for a $500 \mathrm{MW}$ Boiler using fuzzy logic. In the first strategy the PID controller gains are varied based on fuzzy logic rules. Fuzzy rules are utilized on-line to determine the controller parameters based on tracking error and its first time derivative. In the

DOI:10.5121/ijsc.2015.6201 
second strategy the Drum level setpoint is varied based on fuzzy logic rules. Simulation and experimental results of the proposed schemes show good performances of fuzzy based strategies in terms of dynamic and steady state characteristics of all loops. Simulations are performed using MATLAB/SIMULINK

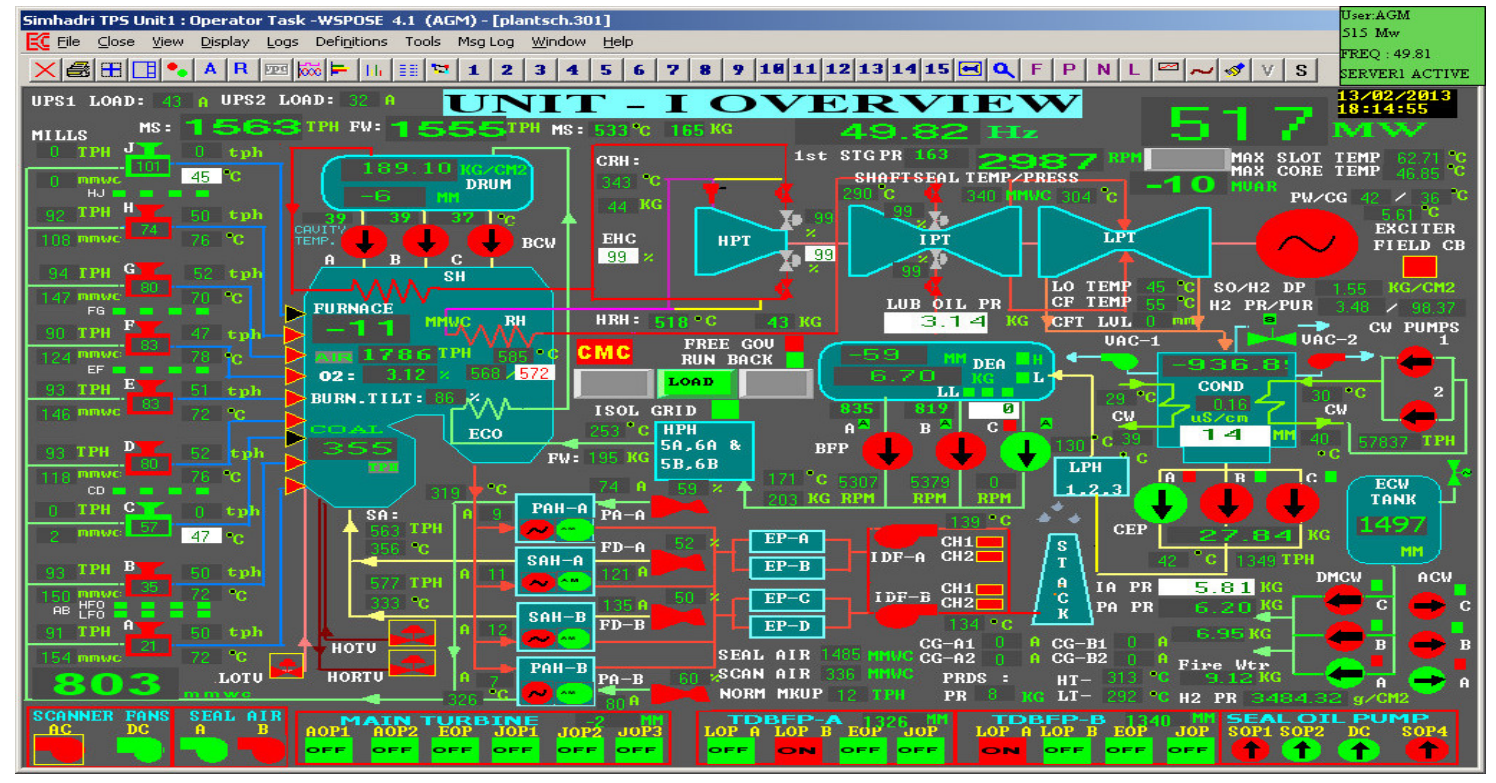

Fig. 1 Overview of a $500 \mathrm{MW}$ unit

\section{SOOT BLOWING SYSTEM}

The soot blowing is done based on a fixed time schedule in many Power stations [1]. This paper propose a Fuzzy logic system designed to advise on Where and When to blow the soot depending on a single attribute called Cleanliness Factor. In contrast to the standard approach regarding soot blowing, cost optimized soot blowing determines continuously, when a specific soot blower group (level) shall be operated. Thus the soot blowing strategy inevitably changes from cleaning of the entire boiler to cleaning of individual heating surfaces.

Furnace and convective pass slagging and fouling have a negative effect on boiler performance, emissions, and unit availability. Furnace Slagging reduces heat transfer to waterwalls and increases amount of heat available to convection pass leading to higher FEGT(Furnace Exit Gas Temperature ), higher steam temperature, higher desuperheating spray flows, reduced performance and higher NOx emission.Convective Pass Slagging and Fouling reduces heat transfer in convection pass leading to lower steam temperature, reduced performance, lower desuperheating spray flows and increased flue gas temperature at boiler exit. [1].However regular sootblowing can result in over-cleaning of furnace walls leading to low steam temperatures , increased moisture levels and erosion damage in last stages of LP turbine, lower turbine and unit power output (due to reduced reheat steam temperature). Sootblowing of boiler convective pass increases heat transfer in that region resulting in increases steam temperatures and desuperheating sprays, and reduces flue gas temperature at boiler exit. Hence for best performance it is important to maintain an optimal balance between furnace and convective pass heat transfer. The resultant requirement is the SootBlowing Optimization [2]. 
The general layout of Soot blowers in a $500 \mathrm{MW}$ is shown in figure 2.

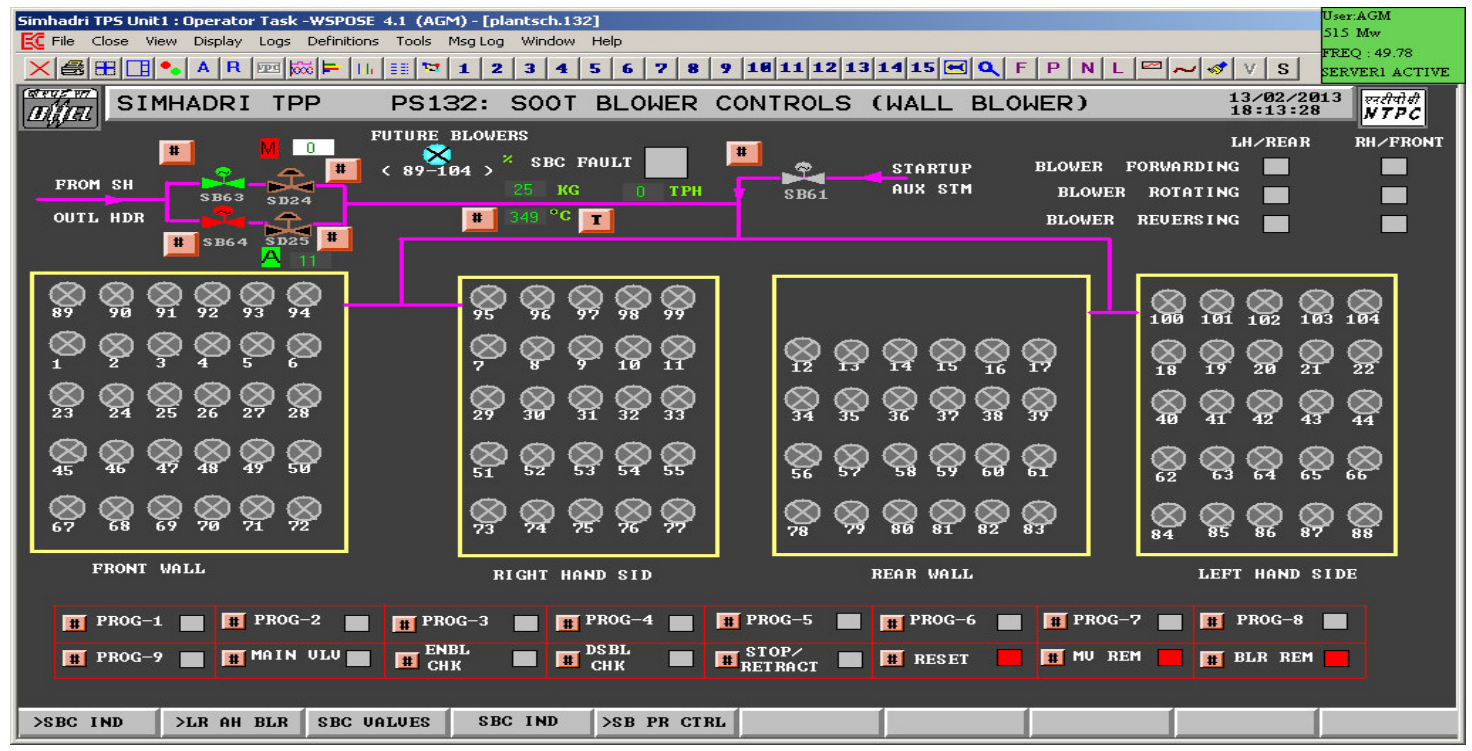

Fig. 2 General Layout of Soot Blowing system in a 500 MW unit

A fixed sootblowing schedule programmed into the sootblower control system indicated that sequential activation of all 88 wall blowers produced large cyclic variations in main steam temperature. The main steam temperature rose as the convection pass was cleaned and fell as slag was scoured from the furnace water walls. Such cycling of main steam temperatures is not desirable because it stresses both the boiler and the steam turbine.

The boiler section fouling status can be quantified by the section cleanliness factor (CF)[3]. By definition, cleanliness factor is the ratio of actual to design heat transfer rate.

\section{FUZZY LOGIC DESIGN}

The fuzzy logic system consists of three different types of entities. -Fuzzy sets, fuzzy variables and fuzzy rules. The membership of a fuzzy variable in a fuzzy set is determined by a function that produces values within the interval $[0,1]$. These functions are called membership functions. The fuzzy rules determine the link between the antecedent and consequent fuzzy variables and are often defined using natural language linguistic terms. A fuzzy if-then rule associates a condition about linguistic variables to a conclusion. The degree the input data matches the condition of a rule is combined with the consequent of the rule to form a conclusion inferred by the fuzzy rule. A fuzzy logic controller consist of three section namely fuzzifier, rule base and defuzzifier as shown in fig.3. The fuzzifier transforms the numeric/crisp value into fuzzy sets; therefore this operation is called fuzzification. The main component of the fuzzy logic controller is the inference engine, which performs all logic manipulations in a fuzzy logic controller. The rule base consists of membership functions and control rules. Lastly, the results of the inference process is an output represented by a fuzzy set, however, the output of the fuzzy logic controller should be a numeric/crisp value. Therefore, fuzzy set is transformed into a numeric value by using the defuzzifier. This operation is called defuzzification[4]. For the proposed study, 
Mamdani fuzzy inference engine is selected and the centroid method is used in defuzzification process.[4,5,6]



Fig. 3 Fuzzy Logic system

A method of estimating the cleanliness factor in furnace is estimated by using fuzzy logic. The following input variables are identified for fuzzification[3].

a) $\mathrm{SH}$ metal temperature

b) Total spray flow

c) Burner Tilt

d) Mill Combination

e) Load

f) Elapsed Time since last soot blowing

The fuzzy sets defining for the above variables are as follows:

LOAD (MW) : \{Low, Average, High $\}$

TEMP oC : \{Low, Normal, High $\}$

SPRAY( TPH): \{Low, Normal, High $\}$

BURNER TILT (deg.) : \{Down, Normal, UP\}

MILLCOMBINATION : \{Lower, Other, UP $\}$

TIME IN HR : \{ Short, Average, Long. \}

The cleanliness factor, chosen as the objective function co ( Command Output), is given by: $\mathrm{CF}$ $(\%)$ - $\{$ Dirty, Clean $\}$

The Linguistic variables and their ranges are given in Table -1

Table -1

\begin{tabular}{|l|l|l|}
\hline Linguistic Value & Notation & Ranges \\
\hline Gaussian MF & LOAD & \\
\hline Low & L & {$[450,480]$} \\
\hline Average & A & {$[470,500]$} \\
\hline High & H & {$[490,520]$} \\
\hline Bell MF & LTSH Temperature & \\
\hline Low & L & {$[520,530]$} \\
\hline Normal & N & {$[530.540]$} \\
\hline High & H & {$[540,550]$} \\
\hline
\end{tabular}


International Journal on Soft Computing (IJSC) Vol.6, No. 2, May 2015

\begin{tabular}{|l|l|l|}
\hline Gaussian MF & Spray & \\
\hline Low & L & {$[20,40]$} \\
\hline Normal & N & {$[25,55]$} \\
\hline High & H & {$[40,60]$} \\
\hline Gaussian MF & Burner Tilt & \\
\hline Down & D & {$[-30,0]$} \\
\hline Normal & N & {$[-20,20]$} \\
\hline Up & U & {$[0,30]$} \\
\hline Gaussian MF & Mill combination & \\
\hline Lower & L & {$[0,5]$} \\
\hline Other & O & {$[.1,9]$} \\
\hline Upper & U & {$[.5,1]$} \\
\hline Bell MF & Time since last SB & \\
\hline Short & S & \\
\hline Average & A & {$[0.4]$} \\
\hline Long & L & {$[2,18]$} \\
\hline Bell MF & Cleanliness Factor & {$[10,24]$} \\
\hline Dirty & D & \\
\hline Clean & C & {$[0,82]$} \\
\hline
\end{tabular}

Considering most of the possible scenarios in the Boiler operating conditions twelve rules are framed for the Fuzzy system. Table-2 and Table-3

Table 2

\begin{tabular}{|l|l|l|l|l|l|l|l|l|}
\hline Rule & Load & Temp & Spray & Tilt & Mill Com & 'Time & Out put & Commd \\
\hline 1 & Lo & Lo & Lo & Nor & Lower & Lo & Clean & 0 \\
\hline 2 & Lo & Hi & Hi & Down & Upper & Hi & Dirty & 1 \\
\hline 3 & Avg & Nor & Nor & nor & other & Avg & Clean & 0 \\
\hline 4 & Avg & Hi & Hi & Down & other & Hi & Dirty & 1 \\
\hline 5 & Hi & Lo & Lo & Nor & Upper & Avg & Clean & 0 \\
\hline 6 & Hi & Hi & Hi & Down & Other & Hi & Dirty & 1 \\
\hline 7 & Hi & Hi & Nor & No & Upper & Avg & Clean & 0 \\
\hline
\end{tabular}


International Journal on Soft Computing (IJSC) Vol.6, No. 2, May 2015

\begin{tabular}{|l|l|l|l|l|l|l|l|l|}
\hline 8 & Avg & Hi & Hi & Down & Lower & Avg & Dirty & 1 \\
\hline 9 & Lo & Nor & Nor & Up & Upper & Avg & Clean & 0 \\
\hline 10 & Hi & Hi & Hi & X & Other & Hi & Dirty & 1 \\
\hline 11 & Hi & Hi & Hi & Down & Lower & Hi & Dirty & 1 \\
\hline 12 & $\mathrm{X}$ & Hi & Hi & Down & X & X & Dirty & 1 \\
\hline
\end{tabular}

Table-3

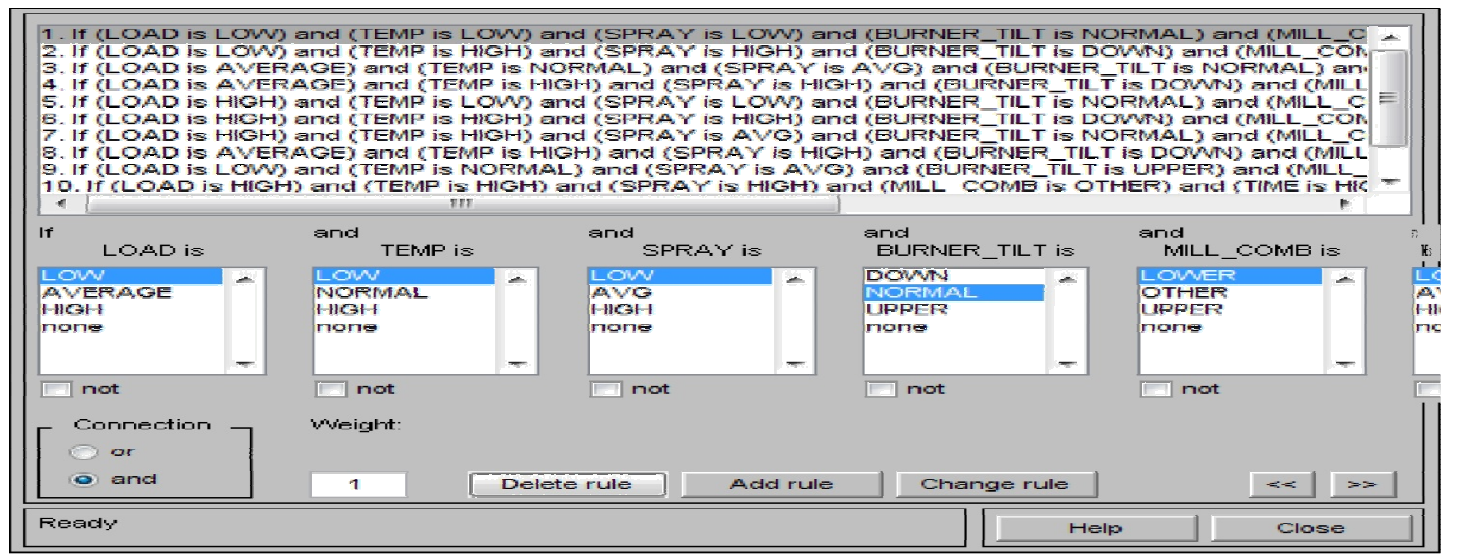

The Configuration of Fuzzy logic using MATLAB is shown in Figure 4. The configuration has 6 input variables and 1 output variable.

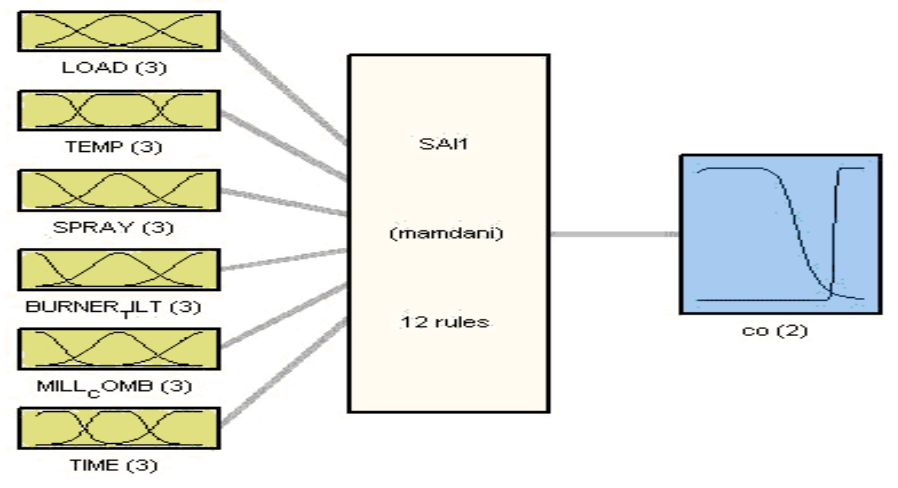

System SA.11: 6 inputs, 1 outputs, 12 rules

Fig. 4 Configuration of Soot blowing System in Fuzzy Logic 


\section{FUZZY INPUT / OUTPUT MEMBERSHIP FUNCTIONS}

The membership function for all the six input variables and one output variable is discussed. The fuzzy sets describing LOAD, TEMP, SPRAY, TILT, MILL COMB, TIME and Output Cleanliness Factor ( CF ) are illustrated in figures 5 to 7.

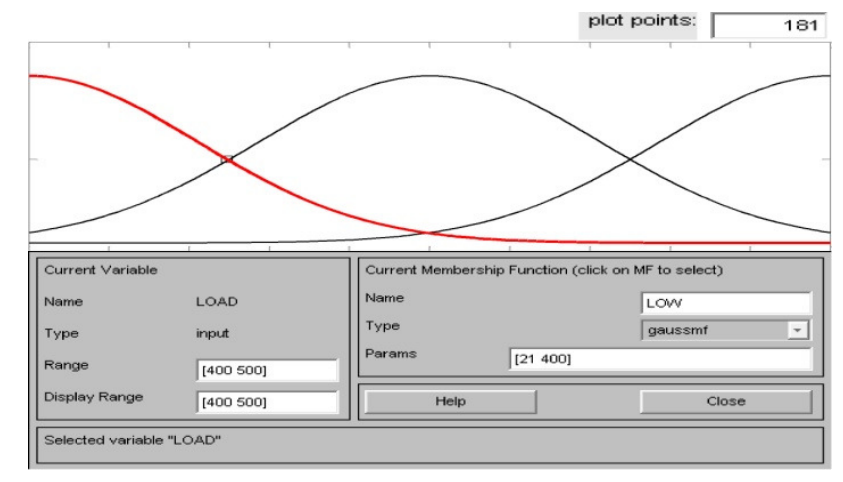

Fig.5 LOAD MF



Fig. 6 SPRAY MF

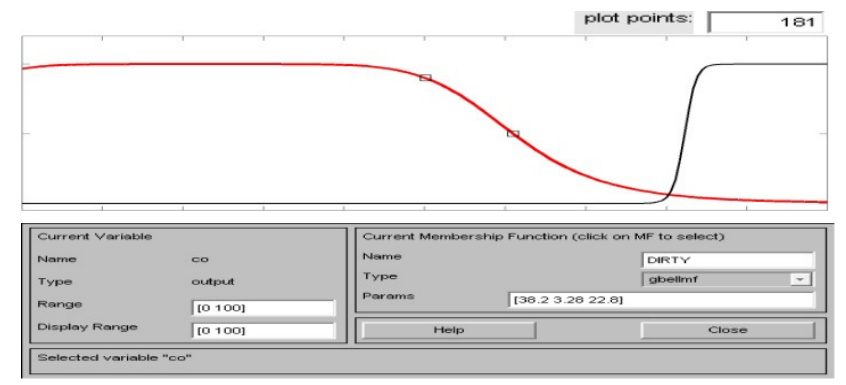

Fig. 7 OUTPUT ( CF ) MF

The surface view of various input combinations and Command Output ( CF ) is shown in Figure 8 


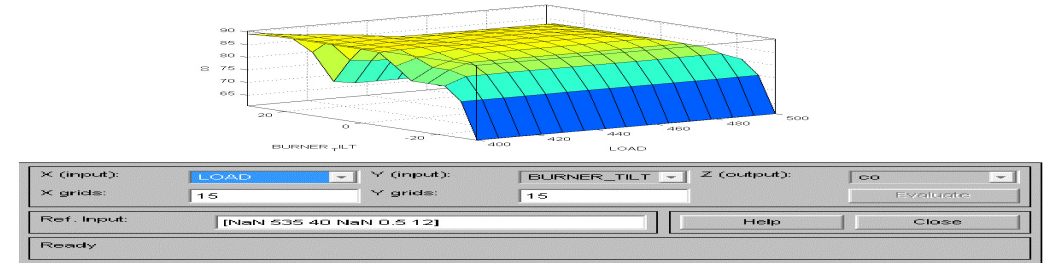

Fig. 8 Surface view of Load, Burner tilt and CO

Results

A MATLAB based program is developed to compute the values of the output for given different input values. This program utilizes 'Fuzzy Inference System'. It calculates the crisp values of the outputs for given inputs. The Fuzzy based soot blowing strategy satisfies the optimization objectives of Lowest operating cost, maximise power generation, Minimises maintenance cost and avoids unmanageable soot build up. The sample results of the MATLAB with six inputs as shown in Table - 4, estimates the Cleanliness Factor from the Fuzzy Soot Blowing Model

Results:

Enter LOAD:(MW):490

Enter SH METAL TEMP: (C): 540

Enter TOTAL SPRAY: (T/H): 20

Enter BURNER TI LT :(degree): -15

Enter MILL COMBINATION: 0.5

Enter TIME SINCE IAST S/B: 15

CLEANLINESS FACTOR OF THE FURNACE is 89.335727

Table-4 Data For estimating CF

\begin{tabular}{|c|c|c|c|c|c|c|}
\hline Load MW & SH temp & Spray & Burner tilt & Mill com & Time $\mathbf{H r}$ & CF \% \\
\hline 490 & 540 & 20 & -15 & 0.5 & 15 & 89.3 \\
\hline 493 & 545 & 25 & -15 & 0 & 24 & 87.3 \\
\hline 492 & 529 & 35 & -10 & $\mathbf{0}$ & 24 & 51.1 \\
\hline 494 & 545 & 30 & 10 & 1 & 22 & 89.7 \\
\hline 497 & 546 & 30 & $\mathbf{0}$ & 1 & 20 & 91 \\
\hline 499 & 525 & 50 & -15 & .6 & 25 & 48.2 \\
\hline 489 & 530 & 20 & 30 & 0 & 22 & 69.8 \\
\hline
\end{tabular}




\section{DRUM LEVEL CONTROL}

The boiler drum is where water and steam are separated. The general layout of a $500 \mathrm{MW}$ Drum level control loop is shown in Figure 9.

The 3 element drum level control is shown in figure 10 . The elements correspond to the three variables that are used as indices of control variables: drum liquid level, feed-water flow, and steam flow. The drum level controller maintains a constant drum level using the flow demand as a set point and uses the drum level process variable as a feedback signal.[5]

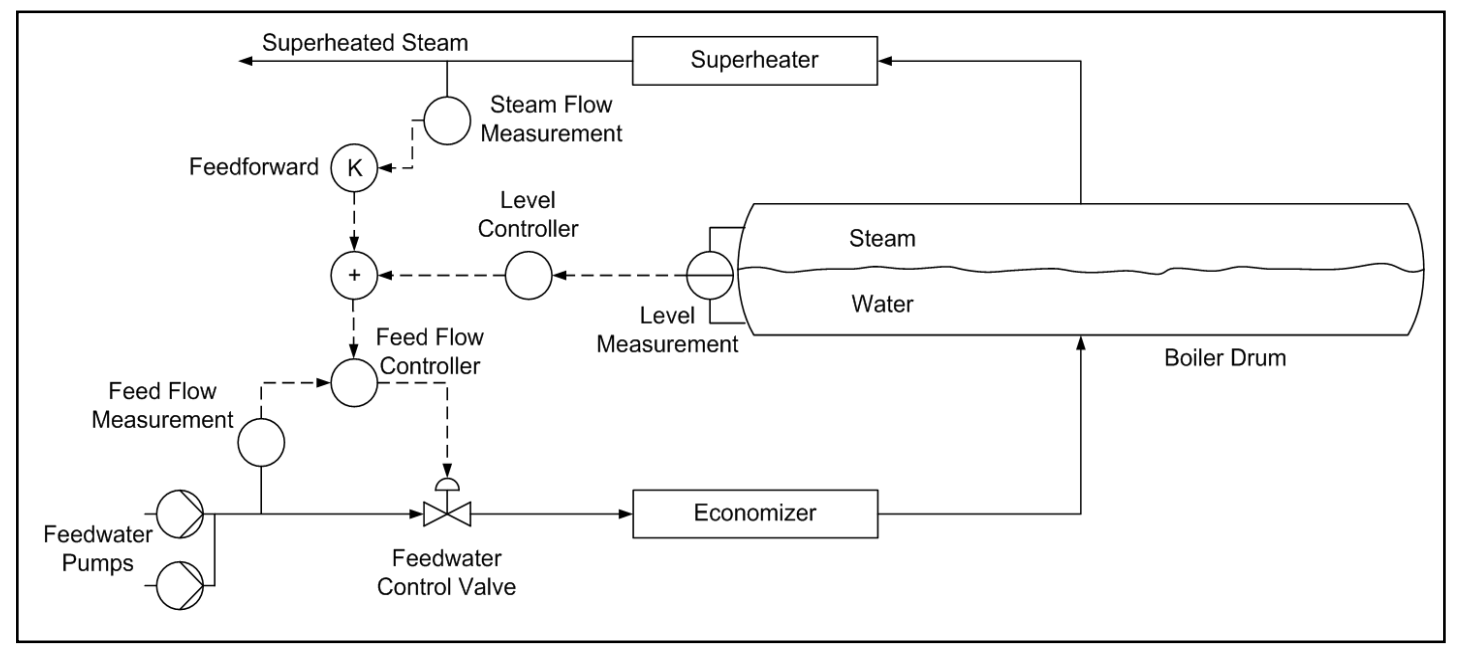

Fig. 9500 MW Drum Level control loop

The Drum level is derived from the following equation:

$\mathrm{h}=\mathrm{DP}+\mathrm{H}(\gamma \mathrm{r}-\gamma \mathrm{s})+(\gamma \mathrm{w}-\gamma \mathrm{s})$

where:

$\mathrm{h}=$ True drum level - Inches

DP $=$ Measured DP head - Inches

$\mathrm{H}=$ Distance between taps - Inches

$\gamma \mathrm{s}=$ Steam Specific Gravity (S.G.)

$\gamma \mathrm{r}=$ Reference leg (S.G.)

$\gamma \mathrm{W}=$ Drum Water (S.G.) 
International Iowrnal on Soft Comnuting (IISC) Vol 6 No 2 Mav 2015

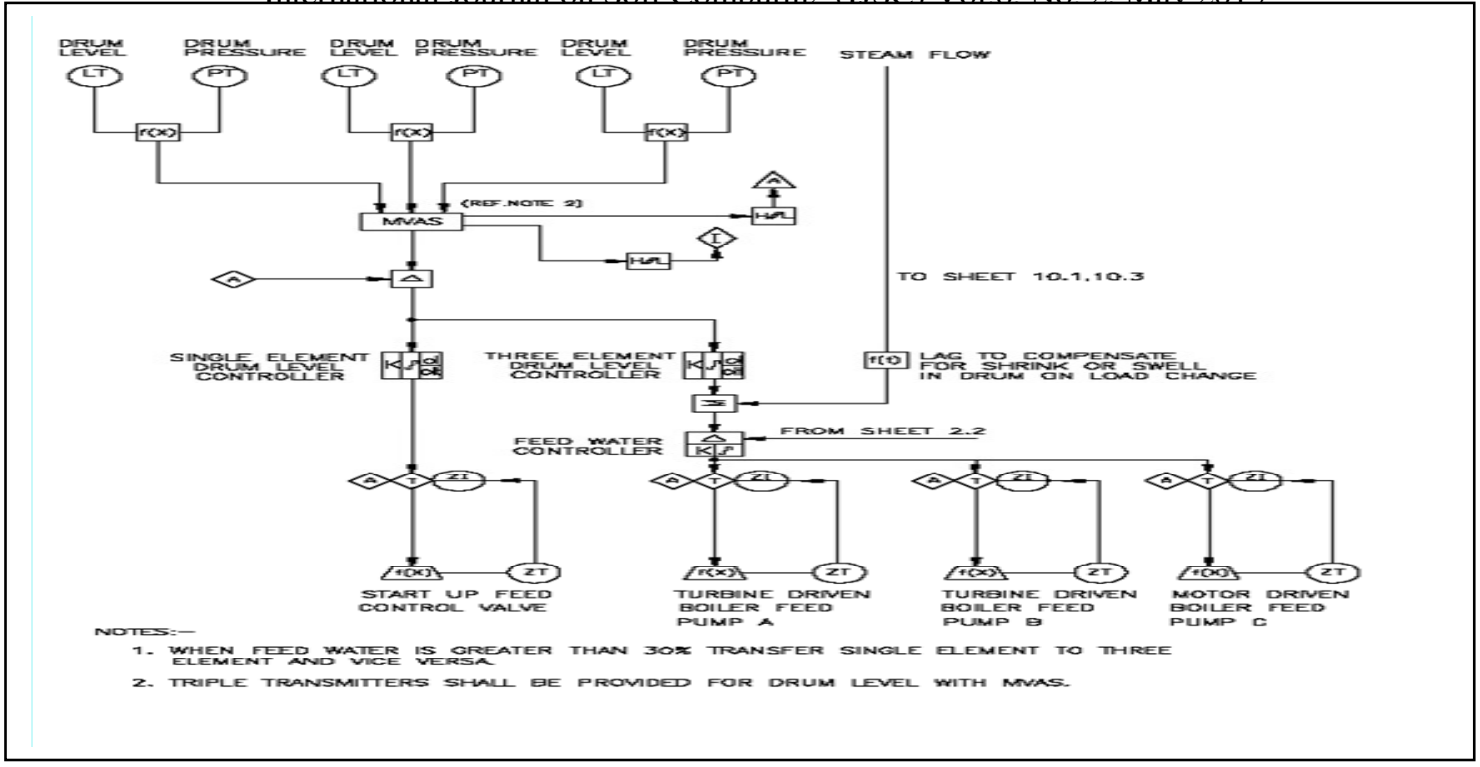

Fig. 10 3-Element Drum Level control loop

PID controller constants obtained during performance guarantee tests done by DCS (Distributed Control System) supplier normally hold good for all times. However due to aging of the plant or due to special operating situations (FGMO- Free governing Mode operation, high fluctuations in coal quality, fuel switching, different load conditions etc) there is a need for changing the PID parameters. Hence a new method is to be devised to change the PID controller parameters.The fuzzy logic controller (FLC) proposed here is intended to show the flexibility, adequacy and reliability of the boiler operation while using the fuzzy logic control action.

Fuzzy gain scheduling is considered to be the most promising alternative combining fuzzy logic with conventional controllers. A rule based scheme for gain scheduling of PID controllers for drum level control is designed in this paper. The new scheme utilizes fuzzy rules and reasoning to determine the controller parameters and the PID controller generates the control signal.The Fuzzy Gain Scheduler proposed in this paper can also be applied to any control loop in the plant, which consists of a PID controller. Fuzzy PID tuning is no longer a pure knowledge or expert based process and thus has potential to be more convenient to implement. The approach taken here is to exploit fuzzy rules and reasoning to generate controller parameters. For the proposed study, Mamdani fuzzy inference engine is selected and the centroid method is used in defuzzification process.[5,6,7]

The PID controller parameters ( $\mathrm{K} \mathrm{p}, \mathrm{Ki}, \mathrm{Kd}$ ) are determined based on the current error e ( $\mathrm{t}$ ) and its derivate $\Delta \mathrm{e}(\mathrm{t})$.Proportional controller has the effect of increasing the loop gain to make the system less sensitive to load disturbances, the integral error is used principally to eliminate steady state errors and the derivative action helps to improve closed loop stability. The parameters $\mathrm{Kp}, \mathrm{Ki}$ and $\mathrm{Kd}$ are thus choosen to meet prescribed performance criteria , classically specified in terms of rise and settling times, overshoot and steady state error, following a step change in the demand signal. 
The fuzzy adapter adjusts the PID parameters to operating conditions, in this case based on the error and its first difference, which characterizes its first time derivative, during process control. The structure of the fuzzy gain scheduler is illustrated in figure. $11[8,9]$

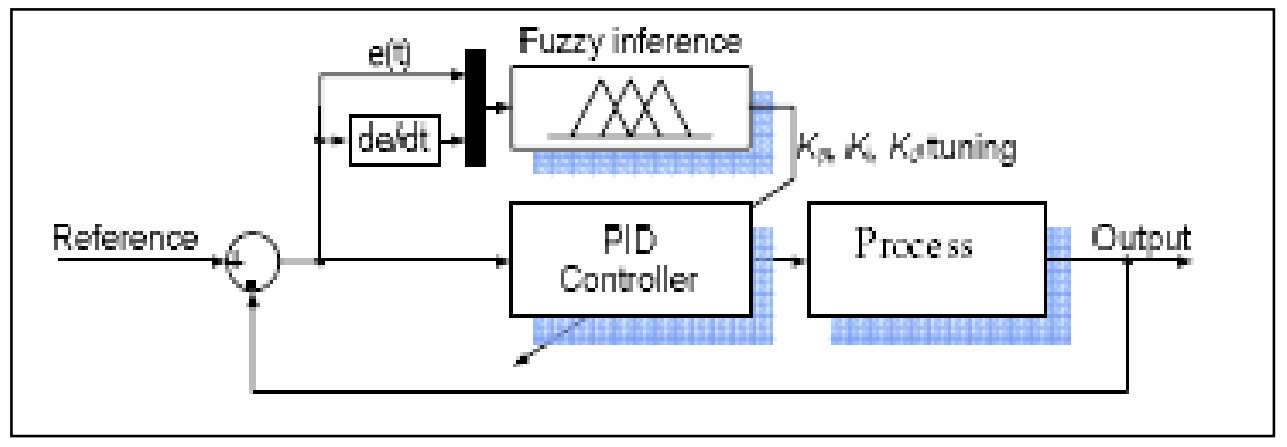

Fig. 11 Fuzzy Gain Scheduler Structure

The Fuzzy Gain Controller of Drum level control loop has 2 inputs ( error e and derivative of error de) and three outputs $\mathrm{Kp}, \mathrm{Ki}$ and $\mathrm{Kd}$. Domain of e is $(-9,9)$, de is $(-6,6)$ and the fuzzy set of e and de are NB( Negative Big ), NM ( Negative Medium ), NS ( Negative Small ), ZE ( Zero ), PS ( Positive Small ), PM( Positive Medium ), PB ( Positive Big ).

Domain of $\mathrm{Kp}$ is $\{0,200\}, \mathrm{Ki}$ is $\{0,8\}$ and $\mathrm{Kd}$ is $\{0,40\}$ and the fuzzy set of $\mathrm{Kp}, \mathrm{Ki}, \mathrm{Kd}$ is $\{\mathrm{NB}$ ( Negative Big ) NM ( negative Medium ), NS ( Negative Small ), ZE ( Zero ), PS ( Positive Small ), PM( Positive medium ), PB ( Positive Big )\} The fuzzy sets are all triangular MF.

When e is large , in order to the system to enable the system to fast track, a large Kp and a small $\mathrm{Kd}$ is selected. In order to prevent the system overshoot to be too large, the integral term is limited. When e is in the medium value, in order to make the system have a smaller overshoot, $\mathrm{Kp}$ is made smaller. In this case Kd impacts on the system response than the other factors . When $\mathrm{e}$ is small, in order to make the system has good steady-state performance, $\mathrm{Kp}$ and $\mathrm{Ki}$ are made larger. Meanwhile, in order to avoid the system oscillating near the set value, the selection of $\mathrm{Kd}$ is critical. Taking into account the interaction between the three parameters and the analysis, the control rules are established for $\mathrm{Kp}, \mathrm{Ki}$, and $\mathrm{Kd}$ as shown in Table 5 to 8

Table-5 Fuzzy tuning rules for Kp Change in error e

\begin{tabular}{|l|l|l|l|l|l|l|l|}
\hline $\begin{array}{l}\text { Change in } \\
\text { derivative } \\
\text { error de }\end{array}$ & NB & NM & NS & ZO & PS & PM & PB \\
\hline NB & PS & ZO & NS & NB & NS & ZO & PS \\
\hline NM & PB & PS & ZO & NS & ZO & PS & PB \\
\hline NS & PB & PB & PS & ZO & PS & PB & PB \\
\hline ZO & PB & PB & PB & PS & PB & PB & PB \\
\hline PS & PB & PB & PS & ZO & PS & PB & PB \\
\hline PM & PB & PS & ZO & NS & ZO & PS & PB \\
\hline PB & PS & ZO & NS & NB & NS & ZO & PS \\
\hline
\end{tabular}


International Journal on Soft Computing (IJSC) Vol.6, No. 2, May 2015

Table-6 Fuzzy tuning rules for Ki

Change in error e

\begin{tabular}{|l|l|l|l|l|l|l|l|}
\hline $\begin{array}{l}\text { Change in } \\
\text { derivative } \\
\text { error de }\end{array}$ & NB & NM & NS & ZO & PS & PM & PB \\
\hline NB & NB & NB & NS & ZO & NS & NB & NB \\
\hline NM & NB & NS & ZO & PS & ZO & NS & NB \\
\hline NS & NS & ZO & PS & PB & PS & ZO & NS \\
\hline ZO & NS & PS & PB & PB & PB & PS & NS \\
\hline PS & NS & ZO & PS & PB & PS & ZO & NS \\
\hline PM & NB & NS & ZO & PS & ZO & NS & NB \\
\hline PB & NB & NB & NS & ZO & NS & NB & NB \\
\hline
\end{tabular}

Table-7 Fuzzy tuning rules for Kd

Change in error e

\begin{tabular}{|l|l|l|l|l|l|l|l|}
\hline $\begin{array}{l}\text { Change in } \\
\text { de }\end{array}$ & NB & NM & NS & ZO & PS & PM & PB \\
\hline NL & ZO & PS & PB & PB & PB & PS & ZO \\
\hline NM & NS & ZO & PS & PB & PS & ZO & NS \\
\hline NS & NB & NS & ZO & PS & ZO & NS & NB \\
\hline ZO & NB & NS & ZO & PS & ZO & NS & NB \\
\hline PS & NB & NS & ZO & PS & ZO & NS & NB \\
\hline PM & NS & ZO & PS & PB & PS & ZO & NS \\
\hline PL & ZO & PS & PB & PB & PB & PS & ZO \\
\hline
\end{tabular}

Table-8 49 Fuzzy rules

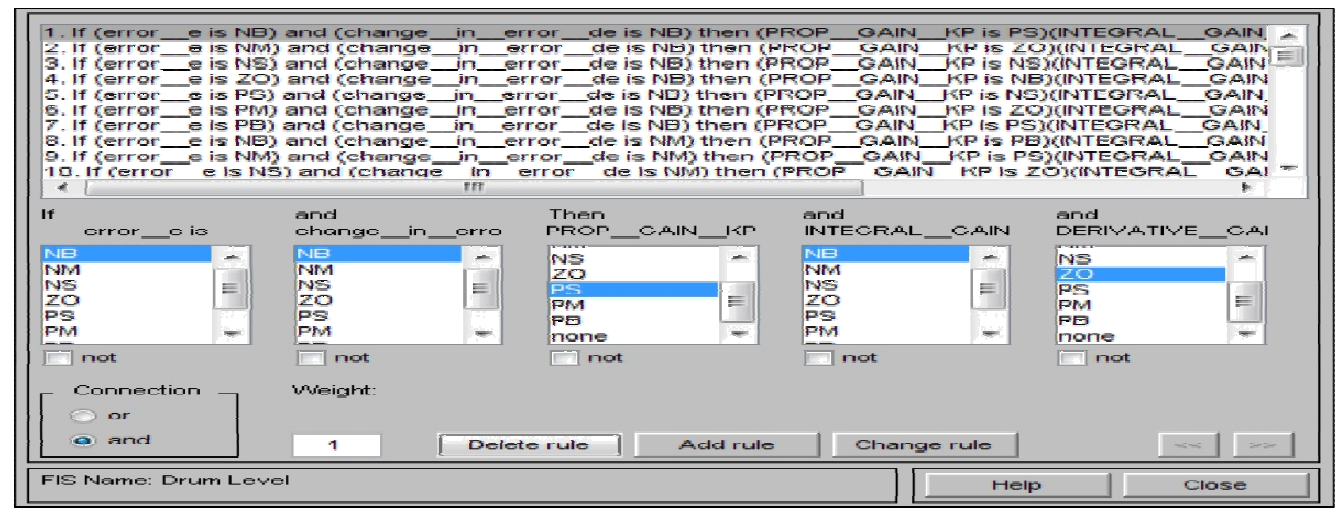


International Journal on Soft Computing (IJSC) Vol.6, No. 2, May 2015



The configuration of the Fuzzy PID control block in MATLAB is shown in Figure 12.

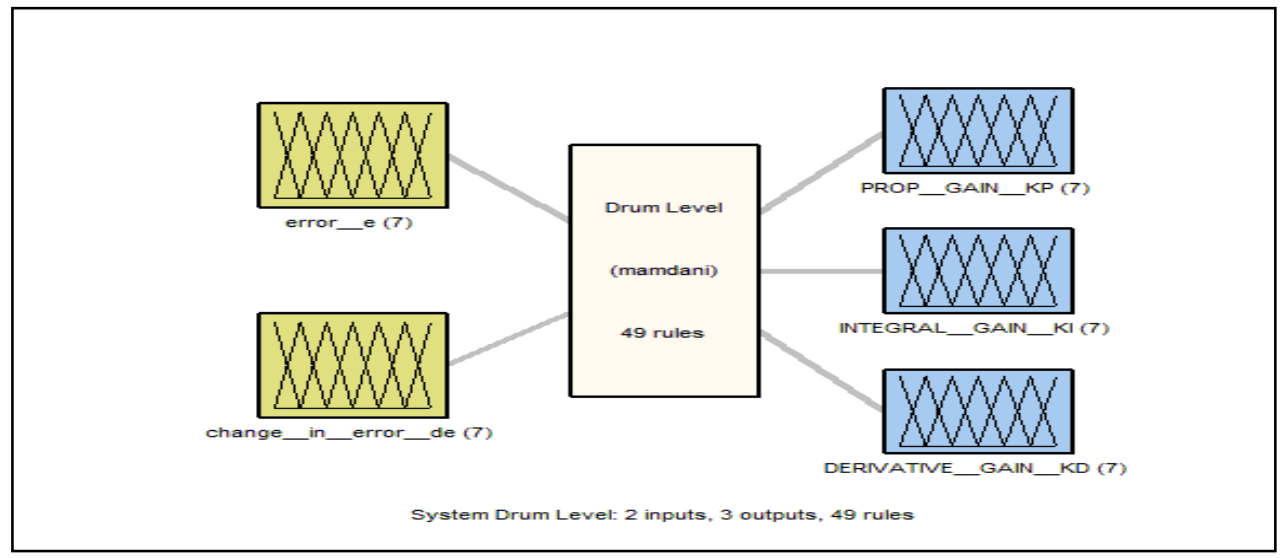

Fig 12. Fuzzy PID configuration

The Simulink Model for the three element Drum Level Control for Conventional PID Control is shown in Figure 13.

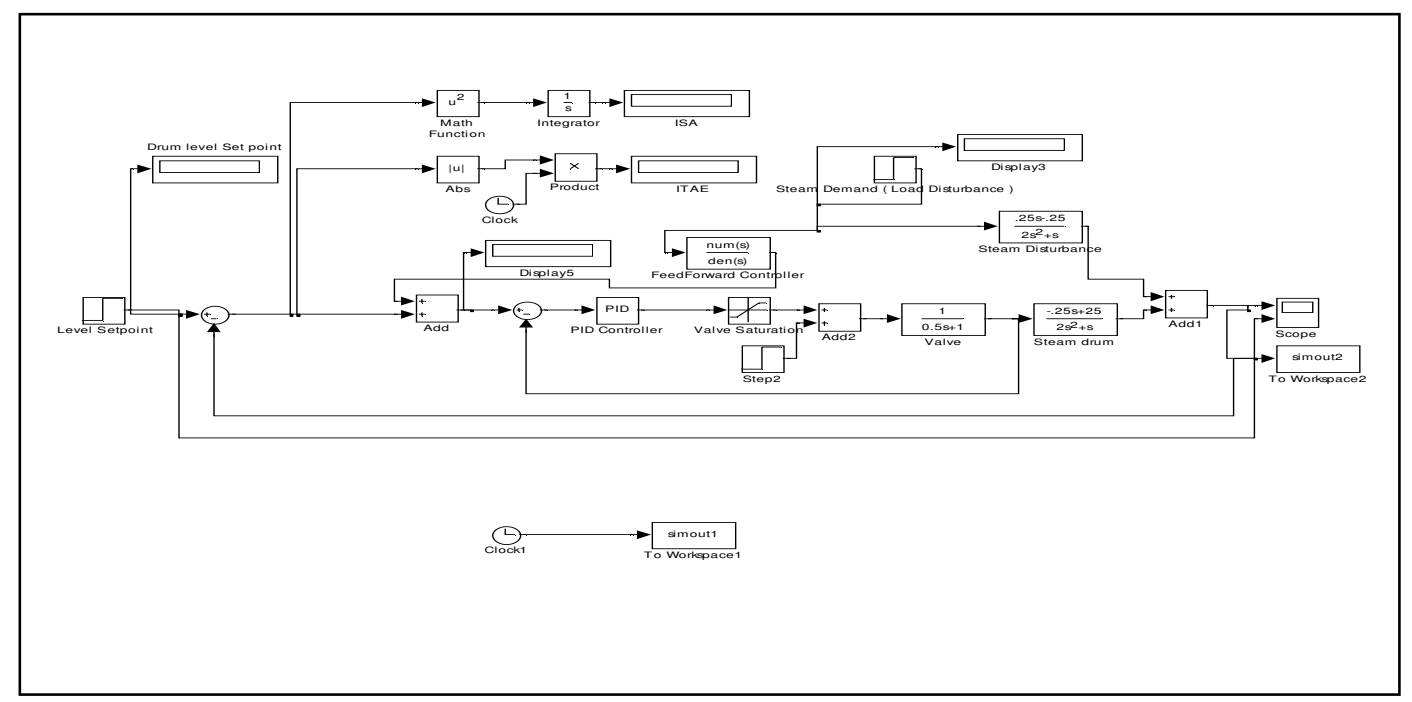


Fig. 13 Simulink Model for the three element Drum Level Control for Conventional PID Control

The Simulink Model for the three element Drum Level Control using Fuzzy Gain Scheduling is shown in Figure 14



Fig. 14 Simulink Model for the three element Drum Level Control using Fuzzy Gain Scheduler

\section{CONCLUSION}

The purpose of this paper is to demonstrate the fuzzy techniques in a Power Station. The intelligent soot blowing system proactively modifies the soot blowing activities in response to real-time events or conditions within the boiler. The intent is to intelligently blow soot while satisfying multiple and specific user defined objectives using on-line, automated techniques. This application provides an asynchronous, event-driven technology that is adaptable to changing boiler conditions.This shall help in optimized soot blowing operation in a Power Plant. This application can further be implemented for all domains in the process plant. This will ensure the conversion of human expertise to knowledge base wherein the linguistic descriptions are translated into numeric data that yield qualitative results. The application of fuzzy logic to design the FGS controller for Drum Level control yields a practical solution that makes use of operation staff's experience and allows independent adjustment of controller parameters to control response. Results of simulation experiments demonstrate that the FGS algorithm may improve the performance of Drum Level control loop well beyond that obtained in conventional PID algorithm. Hence, the FGS proposed approach makes it possible to easily build high-performance tailor-made controllers for any specific control loop in the Power Plant thereby optimizing power plant efficiency and cost. 


\section{REFERENCES}

[1] A. Hazzab1, A. Laoufi1, I. K. Bousserhane1, M. Rahli“Real Time Implementation of Fuzzy Gain Scheduling of PI Controller for Induction Machine Control “

[2] Hamid Bentarzi, Rabahamr Nadir belaidi Samah” A New Approach Applied to a Thermal Power Plant Controller Using Fuzzy Logic plants"

[3] Mohammad Hadi Amoozgar, Abbas Chamseddine, Youmin Zhang "Fault-Tolerant Fuzzy GainScheduled PID for a Quadrotor Helicopter Testbed in the Presence of Actuator Faults"

[4] M. Esfandyari, M. A. Fanaei "Comparsion between classic PID, fuzzy and fuzzy PID controllers “

[5] NTPC Power Plant Model for $500 \mathrm{MW}$ units

[6] Enriquearriag-de-valle and Graciano dieck-Assad"Modelling and Simulation of a Fuzzy supervisory controller for an Industrial Boiler"

[7] A Tanemura,H. Matsumoto Y. Eki S. Nigawara "Expert System for startup scheduling and operation support in fossil power plants"

[8] Xu Cheng ,Richard W. Kephart,Jeffrey J. William "Intelligent SootblowerScheduling for Improved Boiler Operation “

[9] İlhan, Ertuğrul, Hasan Tiryak”An Investigation Of Productivity In Boilers Of Thermal Power Plants With Fuzzy Gain Scheduled PIcontroller

[10] Vjekoslav Galzina, Tomislav Šarić, Roberto Lujić “Application of fuzzy logic in Boiler control”

[11] Bao Gang Hu \& George K I Mann,“A systematic study of Fuzzy P I D controllers.”P 699-712

[12] T P Blanchett . "PID gain scheduling using fuzzy logic"

[13] Cheng Ling," Experimental fuzzy gain scheduling techniques"

[14] Energy Research center, Lehigh university, 610-758-4090

[15] Storm RF and Reilly TJ Coal Fired Boiler performance improvement throughCombustionoptimisation.

[16] Ilamathi $\mathrm{p}$, Selludurai v,Balamurugan $\mathrm{k}$ "Predictive modelling and optimization of power plant nitrogen oxides emission" IAES,2012

[17] Proceedings: " Workshop or Intelligent Soot Blowing Application ' EPRI project Report ,March1 999,TR- 111631

[18] Proceedings," Guidelines for lntelligent Soot blowing Control 'EPRI"2000,TR- 1000410

[19] Intelligent Sootblowing and Waterwall Temperature Monitoring- T. Ziegler AmerenUEM. J. Dooley, A. G. Ferry and M. Daur

[20] Benefits from Selective Sootblowing using Boiler Cleanliness Monitor Stan Piezuch, Black \& Veatch,

[21] Combustion and Sootblowing Optimization using Advanced Instrumention, Control and Artificial Intelligence TechniquesMark A.Rhode,

[22] Sootblowing Optimization-Nenad Sarunac and Carlos E. Romero

[23] I\&C Enhancements for Low NOx Boiler Operation- E Levy, T.Eldredge, C. Romero, and N. Sarunac

[24] Expert system for Boiler efficiency deviations assessment I. Arauzo and C.Cortes

[25] Advanced Technologies Provide New Insights for Assisting Energy from Waste (EfW) Boiler Combustion Monitoring, Operations and Maintenance Stephen G. Deduck, P.E. Covanta Energy, Inc. 


\section{AUTHOR}

T.K. Sai received the B.Tech. degree in electronics and instrumentation engineering from Kakatiya Institute of Technology and Science (KITS), Warangal, in 1986 and the M.Tech. ( part time ) degree from NIT, Warangal in 2002 in Instrumentation. He is currently with NTPC LTD as Additional General Manager ( Control \& Instrumentation ). His research interests include power plant measurement and control, Soft computing \& data mining in power plants. He is Senior member of IEEE with 3 years in Senior Member grade.

K. Ashoka Reddy received the B.Tech. degree in electronics and instrumentation engineering from Kakatiya Institute of Technology and Science (KITS), Warangal, in 1992 and the M.Tech. degree from Jawaharlal Nehru Technical University, Kakinada, India, in 1994 in Electronics. He received the Ph.D degree from the Indian Institute of Technology Madras, Chennai, India, in 2008 in the field of Biomedical Instrumentation. $\mathrm{He}$ is currently Prinicipal and Professor with the Faculty of Electronics and Instrumentation Engineering, KITS. His research interests include biomedical instrumentation, digital signal processing, instrumentation and soft computing. 